\title{
A rare cause of dysphagia in a geriatric patient: Dysphagia aortica
}

\author{
Semih Gülle $₫$, Harun Akar® \\ Department of Internal Medicine, University of Health Sciences, İzmir Tepecik Training and Research Hospital, İzmir, Turkey
}

\begin{abstract}
The aim of this study was to compare mean platelet volume of pregnants with gestational diabetes mellitus to a healthy control group and to detect the relationship between mean platelet volume and fasting blood glucose.
\end{abstract}

Keywords: Aortic aneurysm, dysphagia aortica, dysphagia, geriatry.

Inadequate food intake and malnutrition are common findings among the elderly patient group. Factors that cause malnutrition in elderly patients include chronic diseases, structural oral and dental disorders, impaired cognitive functions, and difficulties in accessing adequate food. ${ }^{[1]}$ In geriatric patients who are evaluated for malnutrition, symptoms such as dysphagia, weight loss, persistent dyspepsia, and iron deficiency anemia are causes for alarm. ${ }^{[2]}$ It is important to evaluate the gastrointestinal system in detail in this patient group. Incidence of iron deficiency anemia increases in elderly patients. In this case report, we present an 83-year-old female patient who presented to our clinic with iron deficiency, B12 deficiency, and long-term dysphagia especially towards solid foods, and was found to have aortic aneurysm and dysphagia aortica.

\section{CASE REPORT}

An 83-year-old female patient presented with complaints of weakness, dizziness and fainting for about three months and was hospitalized in the internal medicine ward with a diagnosis of severe anemia according to her test results.
Physical examination revealed her vital signs were stable, and no remarkable findings other than pale oral and scleral mucosa. Test results were as follows: $\mathrm{Hb}: 7.2 \mathrm{gr} / \mathrm{dL}(\mathrm{N}: 11-14 \mathrm{gr} / \mathrm{dL}$ ), MCV: 65 fL (N: 80-97 fL). Biochemistry results were unremarkable. The patient's vitamin $\mathrm{B} 12$ level was $64 \mathrm{pg} / \mathrm{mL}$ ( $\mathrm{N}: 190-660 \mathrm{pg} / \mathrm{mL}$ ) and iron deficiency was detected. Chest PA radiography of the patient revealed increased opacity near the left hilar and apical regions and chest $\mathrm{CT}$ was requested. Chest $\mathrm{CT}$ revealed enlargement of the pulmonary artery $(46 \mathrm{~mm})$, expanding from the arcus aorta $(58 \mathrm{~mm})$, and $2 \mathrm{~cm}$ mural thrombus. It was also observed that the thoracic aorta exerted severe pressure on the esophagus at the level of the pulmonary artery bifurcation (Figure 1).

Barium esophagus-stomach-duodenum radiography revealed flattened gastric folds and an appearance compatible with external compression at the end of this region with the accumulation of contrast material in the middle region of the esophagus. Difficulty swallowing for the past 2-3 years which caused loss of appetite was believed to be the cause the patient's complaints and subsequent nutritional anemia. Endoscopic

Received: January 25, 2020 Accepted: April 13, 2020 Published online: December 16, 2020

Correspondence: Semih Gülle, MD. Dokuz Eylül Üniversitesi Tıp Fakültesi, İç Hastalıkları Anabilim Dalı, 35340 İnciraltı, İzmir, Türkiye. Tel: +90 541 - 6442466 e-mail: semih.gulle@hotmail.com 


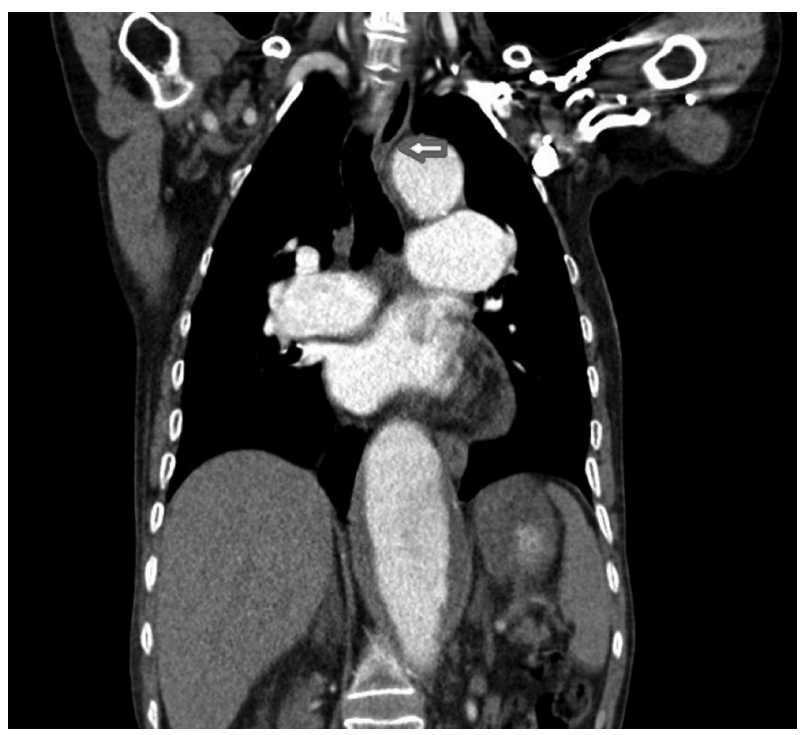

Figure 1. Prominent thoracic aorta and its compression on the esophagus are observed.

imaging could not be performed because of the patient's poor clinical performance. The patient's symptoms were markedly improved following parenteral nutrition, and follow-up was planned with a fluid diet, parenteral vitamins, and iron replacement. The patient's medical treatment was arranged and was called for regular follow-up. The patient was informed about the procedure and written consent was obtained.

\section{DISCUSSION}

Malnutrition due to dysphagia is a common finding in elderly patients. Dysphagia aortica, which is an extremely rare cause of malnutrition, is the mechanical obstruction of the esophagus as a result of external compression. It was first described by Pape in 1932 as difficulty swallowing due to extrinsic compression of the esophagus by an ectatic, tortuous, or aneurysmatic aorta caused by age-related degeneration. ${ }^{[3]}$ Patients are typically elderly, female, diagnosed with hypertension, and expected to be short, often with kyphotic features. Weight loss and intolerance to solid foods are often determined in detailed history. ${ }^{[4]}$ Our patient had similar features to those stated in the literature, since she was a $1.55 \mathrm{~m}$ elderly female patient.

In conclusion, while investigating the causes of dysphagia, the rare cause, dysphagia aortica should also be considered. Evaluating routine radiological assessments as well as the esophagus and neighboring structures with CT when necessary may provide significant benefit leading to diagnosis. ${ }^{[4]}$

\section{Declaration of conflicting interests}

The authors declared no conflicts of interest with respect to the authorship and/or publication of this article.

\section{Funding}

The authors received no financial support for the research and/or authorship of this article.

\section{REFERENCES}

1. Achem SR, Devault KR. Dysphagia in aging. J Clin Gastroenterol 2005;39:357-71.

2. Lind CD. Dysphagia: evaluation and treatment. Gastroenterol Clin North Am 2003;32:553-75.

3. Wilkinson JM, Euinton HA, Smith LF, Bull MJ, Thorpe JA. Diagnostic dilemmas in dysphagia aortica. Eur J Cardiothorac Surg 1997;11:222-7.

4. Ponce J, Gaspar E, Del Val A, Garrigues V, SanchoTello MJ, Carrasquer J. [Dysphagia of vascular origin]. Rev Esp Enferm Dig 1991;80:53-6. 